<smiles>C1=CCCCCC1</smiles>

CrossMark -click for updates

Cite this: Soft Matter, 2015, 11, 806

DOI: $10.1039 / \mathrm{c} 4$ sm90166e

www.rsc.org/softmatter

\section{Correction: Structural heterogeneity of milk casein micelles: a SANS contrast variation study}

Antoine Bouchoux,**ab Jorge Ventureira, ${ }^{\text {ab }}$ Geneviève Gésan-Guiziou, ${ }^{\text {ab }}$ Fabienne Garnier-Lambrouin, ${ }^{a b}$ Peng Qu, ${ }^{\text {ab }}$ Coralie Pasquier, ${ }^{\text {ab }}$ Stéphane Pézennec, ${ }^{a b}$ Ralf Schweins ${ }^{c}$ and Bernard Cabane ${ }^{d}$

Correction for 'Structural heterogeneity of milk casein micelles: a SANS contrast variation study' by Antoine Bouchoux et al., Soft Matter, 2015, DOI: 10.1039/c4sm01705f.

The original manuscript contained an error in the labelling of the $y$-axis in Fig. 7, and in the graphical abstract. Please see the corrected figures below:

Graphical Abstract
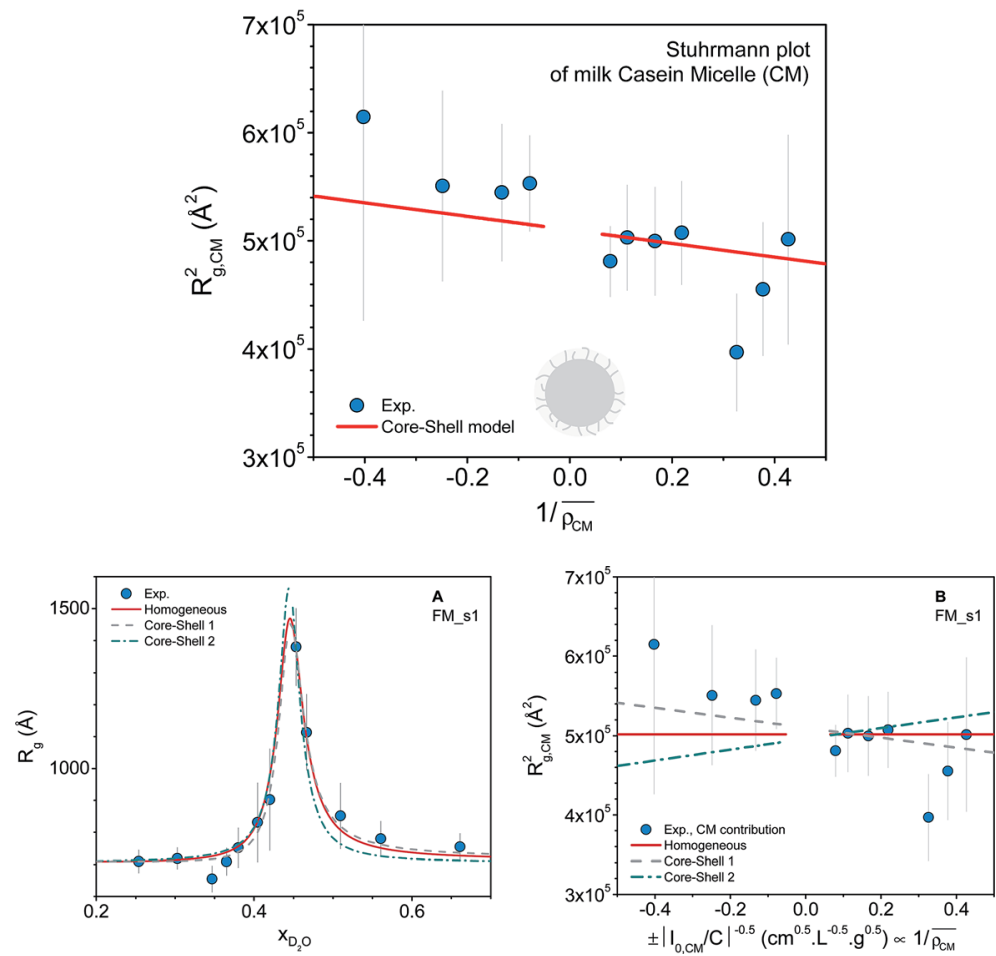

Fig. 7 Using non-homogeneous structural models for modeling the variation of $R_{\mathrm{g}}$ with contrast: an example with casein micelles from fresh milk (FM_s1). The description of the core-shell models is in the text. (A) gives the variation of the apparent radius of gyration $R_{\mathrm{g}}$ (i.e., including the contribution of fat droplets) as a function of $\mathrm{D}_{2} \mathrm{O}$ content. In (B), we use a representation similar to the one used by Stuhrmann, ${ }^{10}$ and that consists of plotting the squared radius of gyration of the casein micelle population $R_{\mathrm{g}, \mathrm{CM}}{ }^{2}$ (i.e., without the contribution of fat droplets) as a function of the reciprocal of the contrast of the micelles, $1 / \overline{\rho_{\mathrm{CM}}}$. Details about the calculation of $R_{\mathrm{g}, \mathrm{CM}}{ }^{2}$ and $1 / \overline{\rho_{\mathrm{CM}}}$ from the experimental data are given in ESI part F. $\dagger$

The Royal Society of Chemistry apologises for these errors and any consequent inconvenience to authors and readers.

aINRA, UMR1253 Science et Technologie du Lait et de l'OEuf, F-35042 Rennes, France.E-mail: Antoine.Bouchoux@insa-toulouse.fr

${ }^{b}$ Agrocampus Ouest, UMR1253 Science et Technologie du Lait et de l'OEuf, F-35042 Rennes, France

${ }^{c}$ Institut Laue-Langevin, DS/LSS group, F-38042 Grenoble Cedex 9, France

${ }^{d}$ Laboratoire CBI, CNRS UMR8231, ESPCI, 10 rue Vauquelin, F-75231 Paris Cedex 05, France

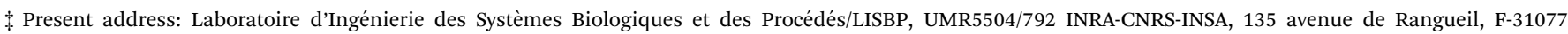
Toulouse Cedex 04, France. 